\title{
Mejoró la subutilización de servicios de salud en los Estados Unidos de Norteamérica, pero no el sobreuso
}

The underutilization of health services has improved in USA, but not the overuse

\section{Objetivos}

Determinar si el sobreuso y el "mal uso" de los servicios ambulatorios de salud han descendido en la última década.

\section{Diseño, lugar y evaluación de resultados principales}

Serie temporal de estudios de corte transversal basados en encuestas nacionales de atención médica ambulatoria (19981999, 2008-2009) realizados en EE.UU. Fueron definidas tres categorías de uso de sistemas de salud: 1) subutilización: la no realización de una prestación de salud cuando existe evidencia de que sus beneficios superan a sus riesgos: 2) sobreuso: la realización de un prestación ante evidencia de que los riesgos superan a los beneficios; 3 ) mal uso: el cuidado médico inade-
Kale y col. Arch Intern Med. 2013;173(2):142-8 cuado. Fueron evaluadas las tasas de uso de 22 indicadores que representan las tres categorías descriptas.

\section{Resultados}

Fueron evaluadas 79.083 visitas (edad media 50,9 años) en el período 1998-1999; y 102.980 en el periodo 2008-2009 (edad media 54,2). En este último preíodo hubo mayor cantidad de personas afiliadas al sistema Medicare, sin diferencias estadísticamente significativas en el resto de las variables recolectadas: (sexo, raza, etnia, motivo de consulta y región). Se constató mejoría en seis de los nueve indicadores de subutilización y sólo en dos de los once indicadores de sobreuso. Ver tabla 1.

Tabla 1: Comparación de menor uso, sobreuso y mal uso entre 1999 y 2009 en EEUU

\begin{tabular}{|c|c|c|c|}
\hline & \multirow[b]{2}{*}{ Indicadores } & \multicolumn{2}{|c|}{$\%$ (IC 95\%) } \\
\hline & & 1999 & 2009 \\
\hline \multirow{9}{*}{ 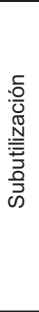 } & Terapia antitrombótica para fibrilación auricular & $45,9(33,4$ a 59,0$)$ & $71,9(66,5$ a 76,7$)$ \\
\hline & IECA para IC & $44,8(37,6$ a 52,4$)$ & $41,6(37,4$ a 45,9$)$ \\
\hline & Aspirina para enfermedad coronaria & $28,4(22,4$ a 35,3$)$ & $64,5(60,2$ a 68,5$)$ \\
\hline & Beta-bloqueantes para IC & $20,6(11,8$ a 33,4$)$ & $59,7(53,8$ a 65,4$)$ \\
\hline & Beta-bloqueantes para enfermedad coronaria & $28,1(22,1$ a 35,2$)$ & $55,2(51,7$ a 58,8$)$ \\
\hline & Antiplaquetarios para el ACV isquémico & $51,0(36,7$ a 65,2$)$ & $48,7(41,1$ a 56,3$)$ \\
\hline & Estatinas para enfermedad coronaria & $26,8(19,7$ a 35,2$)$ & $58,6(54,1$ a 63,0$)$ \\
\hline & Estatinas para pacientes $\geq 40$ años con diabetes & $12,1(9,23$ a 15,6$)$ & $36,2(33,4$ a 39,2$)$ \\
\hline & Terapia farmacológica para la osteoporosis & $35,3(23,6$ a 48,9$)$ & $45,1(37,8$ a 52,7$)$ \\
\hline \multirow{11}{*}{ 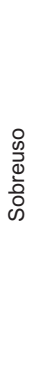 } & Rastreo de cáncer de próstata en hombres $\geq 74$ años & $3,5(2,4$ a 5,1$)$ & $5,7(4,6$ a 7,0$)$ \\
\hline & ECG como parte del control de salud & $6,1(3,1$ a 11,5$)$ & $11,3(5,9$ a 20,8$)$ \\
\hline & Análisis de orina como parte del control de salud & $39,9(29,5$ a 51,4$)$ & $25,3(17,2$ a 35,6$)$ \\
\hline & Rx de tórax como parte del control de salud & $4,7(2,4$ a 9,1$)$ & $7,0(3,2$ a 14,5$)$ \\
\hline & Hemograma como parte del control de salud & $22,3(13,1$ a 35,3$)$ & $37,9(26,8$ a 50,6$)$ \\
\hline & Rastreo de cáncer cervical en mujeres $\geq 64$ años & $3,1(2,6$ a 3,8$)$ & $2,2(1,8$ a 2,7$)$ \\
\hline & Rastreo de cáncer de mama en mujeres $\geq 74$ años & $2,1(1,5$ a 3,0$)$ & $2,6(2,0$ a 3,5$)$ \\
\hline & Rx por lumbalgia en adultos entre 18 y 55 años & $19,1(15,2$ a 24,1$)$ & $22,8(18,4$ a 27,9$)$ \\
\hline & Antibióticos en cuadro de vía aérea superior & $37,8(34,4$ a 41,3$)$ & $40,2(36,6$ a 43,9$)$ \\
\hline & Antibióticos en bronquitis aguda & $60,8(51,4$ a 69,5$)$ & $58,8(47,3$ a 69,4$)$ \\
\hline & Antibióticos en exacerbación asmática & $22,3(13,9$ a 33,9$)$ & $6,8(4,9$ a 9,3$)$ \\
\hline \multirow{2}{*}{$\begin{array}{l}\frac{O}{\mathscr{D}} \\
\frac{\pi}{2} \\
\frac{\pi}{2}\end{array}$} & $\begin{array}{l}\text { Prescripción de antibiótico diferente a nitrofurantoína } \\
\text { quinolonas o TMS en mujeres con ITU no complicada }\end{array}$ & $24,9(18,1$ a 33,2$)$ & $2,7(1,2$ a 5,7$)$ \\
\hline & $\begin{array}{l}\text { Prescripción de fármacos no apropiados en adultos } \\
\text { mayores de } 64 \text { años }\end{array}$ & $6,5(5,8$ a 7,3$)$ & $7,2(6,3$ a 8,1$)$ \\
\hline
\end{tabular}

ACV: accidente cerebrovascular; ECG: electrocardiograma; ICC: insuficiencia cardiaca; IECA: Inhibidores de la enzima convertidora de angiotensina; ITU: infección del tracto urinario; Rx: radiografía; TMS: trimetoprima-sulfametoxazol.

\section{Conclusión}

La mejoría en los indicadores de subutilización fue mayor que la de los de cuidado inapropiado (sobreuso y mal uso).

\section{Comentario}

El incremento en el costo de las prestaciones de salud plantea la necesidad de identificar las insuficiencias de los sistemas de salud y si bien estudios recientes comunicaron mejoras respecto a la subutilización de los servicios, era incierto si lo mismo ocurría con el sobreuso y el "mal uso"'. Por otro lado, a pesar de que los programas de calidad se han enfocado en garantizar la prestación de senicios adecuadamente indicados, recientemente se han iniciado esfuerzos para reducir también la indicación de prácticas no recomendadas ya que las prestaciones excesivas pueden conducir al sobrediagnóstico y derivar en tratamientos inapropiados, no exentos de efectos adversos.

\section{Conclusiones del comentador}

La mejoría en la subutilización pero no en el cuidado inapropiado podría explicarse en que el foco de los programas de mejoramiento de la calidad no ha sido la disminución del número de prestaciones, sino lo contrario. Si bien se hace necesario optimizar estos indicadores a la luz del costo de los servicios de salud, plantear políticas de reducción de prestaciones puede encontrar resistencia tanto en el ámbito médico como político.

Maria Victoria Salgado [ Servicio de Medicina Familiar y Comunitaria. Hospital Italiano de Buenos Aires. maria.salgado@ hiba.org.ar]

Salgado M. Mejoró la subutilización de servicios de salud en los Estados Unidos de Norteamérica, pero no el sobreuso. Evid Act Pract Ambul. 2014 17(4). Oct-Dic 133. Comentado de: Kale M y col. Trends in the Overuse of Ambulatory Health Care Services in the United States. Arch Intern Med. 2013;173(2):142-8. PMID: 23266529.

Referencias

1. Orszag P. McAllen Medicine. Office of Management and Budget Blog. http://www.whitehouse.gov/omb/blog/09/05/28/McAllenMedicine/. Acceso 26 de Agosto de 2014. 2. Stafford R. Quality of US outpatient care: temporal changes and racial/ethnic disparities. Arch Intern Med. 2005;165(12):1354-1361. 